\title{
Skill in Simulating Australian Precipitation at the Tropical Edge*
}

\author{
Penelope MAHer $^{+}$And Steven C. Sherwood \\ Climate Change Research Centre, and ARC Centre of Excellence for Climate System Science, \\ University of New South Wales, Sydney, New South Wales, Australia
}

(Manuscript received 6 August 2015, in final form 2 December 2015)

\begin{abstract}
Expansion of the tropics will likely affect subtropical precipitation, but observed and modeled precipitation trends disagree with each other. Moreover, the dynamic processes at the tropical edge and their interactions with precipitation are not well understood. This study assesses the skill of climate models to reproduce observed Australian precipitation variability at the tropical edge. A multivariate linear independence approach distinguishes between direct (causal) and indirect (circumstantial) precipitation drivers that facilitate clearer attribution of model errors and skill. This approach is applied to observed precipitation and ERA-Interim reanalysis data and a representative subset of four models from phase 5 of the Coupled Model Intercomparison Project (CMIP5) and their CMIP3 counterparts. The drivers considered are El Niño-Southern Oscillation, southern annular mode, Indian Ocean dipole, blocking, and four tropical edge metrics (position and intensity of the subtropical ridge and subtropical jet). These models are skillful in representing the covariability of drivers and their influence on precipitation. However, skill scores have not improved in the CMIP5 subset relative to CMIP3 in either respect. The Australian precipitation response to a poleward-located Hadley cell edge remains uncertain, as opposing drying and moistening mechanisms complicate the net response. Higher skill in simulating driver covariability is not consistently mirrored by higher precipitation skill. This provides further evidence that modeled precipitation does not respond correctly to large-scale flow patterns; further improvements in parameterized moist physics are needed before the subtropical precipitation responses can be fully trusted. The multivariate linear independence approach could be applied more widely for practical model evaluation.
\end{abstract}

\section{Introduction}

One of the most important questions about future climate change is how it will affect regional precipitation patterns. The principal tool available to answer this question is general circulation models. Model responses to emission scenarios are consistent in some aspects such as the drying tendency in subtropical regions and increased precipitation at high latitudes (Collins et al. 2013). However, some model responses are inconsistent; for example, there is no consensus on whether precipitation will increase or decrease in many regions. This is true in Australia, where

\footnotetext{
* Supplemental information related to this paper is available at the Journals Online website: http://dx.doi.org/10.1175/JCLI-D-15-0548.s1.

${ }^{+}$Current affiliation: University of Exeter, Exeter, United Kingdom.
}

Corresponding author address: Penelope Maher, University of Exeter, Laver Building, North Park Road, Exeter EX4 4QH, United Kingdom.

E-mail: p.maher@exeter.ac.uk models can have opposite precipitation projections (see Fig. 4.2 of Australian Academy of Science 2015). Some regions have more consistency than others, such as southwest Western Australia, but it is not clear if projections are similar for consistent reasons or if they can be trusted. It is important to confirm whether consistent model responses are correct and to minimize inconsistent model responses where possible. Natural variability in the earth system further complicates modeling changes in regional precipitation as trends in most continental locations cannot yet be unambiguously separated from natural variability.

Global climate models in general predict drying in the subtropics and moistening at higher latitudes in future climates. These changes are a consequence of two factors: the poleward shift of circulation and a thermodynamically driven wet-get-wetter precipitation response to warming (Held and Soden 2006; Chou et al. 2007). However, in spite of robust indicators that the observed tropical edge has expanded by $2^{\circ}-5^{\circ}$ since 1979 (Seidel et al. 2008; Lucas et al. 2013) and that the atmosphere has warmed, even the zonally averaged global trends in 
observed precipitation do not yet clearly match those predicted (Zhang et al. 2007). This raises questions about whether subtropical precipitation is connected to general circulation in the expected ways. Moreover, models predict significant zonal variations in the meridional precipitation response pattern (Collins et al. 2013), such that even if the meridional response were known confidently, regional changes will be more complicated.

A number of circulation model biases exist that can complicate our interpretation of model projections. In particular, the modeled expansion rate of the Hadley cell is significantly slower than observations (Johanson and $\mathrm{Fu}$ 2009) and model trends in the Southern Hemisphere subtropical ridge strengthening is underestimated (Nguyen et al. 2015).

Australia is particularly vulnerable to a poleward shift of precipitation patterns because of its subtropical location and dry climate, with most of the population located within the seasonal range of the tropical edge. In southwest Western Australia, the observed drying trend has been attributed to anthropogenic climate change (Hope et al. 2006; Timbal and Drosdowsky 2012; Cai et al. 2012). Autumn drying in southeastern Australia has been attributed to a poleward shift in the Hadley cell (Cai and Cowan 2013) and changes in the subtropical ridge (Timbal and Drosdowsky 2012).

Observed precipitation variability in Australia has been the focus of numerous studies. Previous studies have found that precipitation is influenced by El NiñoSouthern Oscillation (ENSO), Indian Ocean dipole (IOD), southern annular mode (SAM), eastern Australian atmospheric blocking, and the position and intensity of the subtropical jet and subtropical ridge (Cai et al. 2012; Frederiksen and Frederiksen 2007; Cai et al. 2011a; Timbal and Drosdowsky 2012; Larsen and Nicholls 2009; Meneghini et al. 2007; Risbey et al. 2009; Hendon et al. 2007).

Risbey et al. (2009) identified that in Australia multiple drivers can act as the lead driver within a region, and the spatial pattern of the lead driver changes seasonally (see their Fig. 15). Studies have mostly focused on the cool seasons, in which robust drying trends are observed (Timbal and Drosdowsky 2012), the IOD is active (Risbey et al. 2009), the subtropical ridge is strongest (Drosdowsky 2005), and precipitation in the southern parts of the continent is dominated by eastward-moving midlatitude cyclones within the storm tracks.

Uncertainty still remains in attributing the influence of each source of variability. This is due in part to limitations in the methods used in previous studies that are often limited to assessing relationships based on correlations and fidelity to past climate. These methods often do not distinguish between direct and indirect relationships nor provide sufficient insight into how changes to these drivers will influence precipitation variability. Previous studies typically look at one driver in isolation; exceptions include (but are not limited to) Meyers et al. (2007), Risbey et al. (2009), Cai et al. (2011a), and Fierro and Leslie (2013). Furthermore, nonlinearities in the relationships between drivers and precipitation are often not considered; exceptions include Whan et al. (2014), who investigate nonlinearities in the relationships between the subtropical ridge and precipitation, and King et al. (2013, and references therein) with asymmetries between IOD and ENSO.

Very few studies have investigated the influence of precipitation drivers on modeled Australian precipitation with equivalent scrutiny as in observational studies. One such study is Risbey et al. (2011), who investigated the correlations between precipitation and drivers using the ACCESS atmospheric model. They concluded that model improvements are needed in order to reproduce teleconnecting processes: ACCESS successfully captured the wintertime interaction between precipitation and atmospheric blocking but not with ENSO, SAM, or IOD. Other studies have focused on the tropical oceans or monsoon regions (Cai et al. 2009; Jourdain et al. 2013).

A further limitation of previous observational studies is that a priori judgments are made about the most important drivers. These assumptions are then validated by removing their influence from the precipitation signal and assessing its impact. Yet, interactions between precipitation drivers are known to be important, and for model evaluation studies it is better if the strongest (or most proximate) relationships are identified, rather than correlations that could be mediated through another mechanism that was possibly overlooked.

Separating the independent contributions of precipitation drivers is difficult as they can be highly correlated, especially the subtropical ridge position and its intensity. A previous study by the authors (Maher and Sherwood 2014, hereafter MS14) applied a new approach to isolate wintertime Australian precipitation drivers. This objective approach was used to infer that a poleward-located tropical edge is predominately associated with drying in southwestern and southeastern Australian during winter. MS14 also showed that the precipitation response to tropical edge metrics could be separated from those associated with more traditional drivers, such as ENSO and IOD. In particular, a strong and poleward subtropical ridge was found to cause drying in most regions examined, both directly and indirectly through its interaction with blocking. MS14 found drying due to a strong ridge may be canceled out by coinciding moistening effects directly associated with a poleward ridge, also seen by Cai et al. (2011a), or 
indirectly via strong blocking, showing the importance of examining the components of the signal in addition to the net effect.

To our knowledge, no published multimodel evaluation efforts have specifically evaluated the ability of climate models to simulate the observed interactions between interannual sources of large-scale variability at the tropical edge and their effect on precipitation in Australia. The aim of this study is to assess model skill in reproducing observed Australian precipitation variability at the tropical edge. This will identify model shortcomings and assist in model development. This will be achieved by addressing the following questions:

1) Is modeled Australian precipitation skillful?

(i) Can CMIP5 models simulate the interactions between large-scale interannual drivers and their influence on Australian precipitation in (statistical) isolation?

(ii) Have current-generation models improved on the previous generation of models in either of these respects?

2) Can models simulate the influence of the tropical edge on Australian precipitation?

(i) Are the observed links identified by MS14 in winter prevalent in other seasons?

(ii) Can models reproduce the observed Australian precipitation response in each season due to natural variability in the tropical edge?

Australia is the focus of this study because this subtropical region is likely to be affected by the expansion of the tropics, is influenced by many sources of largescale variability, and is a region where models are not consistent in how precipitation will change in the future. Each season is considered, expanding on the observational analysis of MS14 beyond winter. Winter remains the primary focus as the winter Hadley cell is strongest, and in this season robust drying trends occur in two of the five regions considered.

Only natural variability is considered, not trends in anthropogenic changes to circulation and precipitation. We anticipate that responses to interannual shifts of the tropical edge due to natural variability will assist in interpreting the forced responses, gradual shifts over time, and models reliability in simulating circulation and precipitation.

The multivariate linear independence approach used by MS14 (see section 2e) is used to determine the interactions between the variability indices (see section $2 \mathrm{~b}$ ) and regional precipitation (see section 2a). The physical mechanisms connecting known Australian precipitation drivers are discussed in more detail for winter (see section 3a) and in other seasons (see section
$3 b)$. In section 4 the skill scores (defined in section $2 \mathrm{f}$ ) of Coupled Model Intercomparison Project (CMIP) models (defined in section $2 \mathrm{c}$ and validated in section $2 \mathrm{~d}$ ) to reproduce the observed interactions between variability indices and regional precipitation is examined. In section 5 the observed and CMIP5 model precipitation response is interpreted for a poleward-located Hadley cell edge within the context of natural variability. Conclusions are drawn in section 6 .

\section{Methods and data}

\section{a. Precipitation time series}

Precipitation in five regions is considered, as identified by MS14, based on earlier studies: southeastern Australia (SEA), southwestern Western Australia (SWWA), eastern New South Wales (ENSW), southeastern Queensland (SEQ), and the Murray-Darling basin (MDB). The regions can be seen in Fig. 1. Observed monthly mean precipitation data from the Australian Water Availability Project (AWAP; Jones et al. 2009) is used in this study for a 30-yr period from 1979 to 2008. In each region the precipitation time series is calculated by removing the seasonal cycle from the precipitation data in each grid box and then averaging over the region of interest. The linear trend is then removed from the time series within each region. Each time series is then normalized to unit variance by removing the long-term mean and dividing by the standard deviation.

\section{b. Variability indices}

The modes of variability (ENSO, SAM, and IOD), atmospheric blocking index, and several variables associated with the edge of the tropics (herein collectively referred to as variability indices) are the same as used by MS14. The atmospheric component of ENSO is measured by the Southern Oscillation index (SOI; Trenberth 1984), SAM is measured by the first principal component of $850-\mathrm{hPa}$ geopotential height field (Thompson and Wallace 2000), IOD is measured by the dipole mode index (DMI; Saji et al. 1999), and atmospheric blocking is measured by the blocking index (BI) along the $140^{\circ}$ meridian (Wright 1994; Pook and Gibson 1999).

The latitude of the subtropical jet position is estimated as the zero crossing of the mass streamfunction at $500 \mathrm{hPa}$, and its intensity is measured at the zerocrossing latitude using a cubic spline fit of the $250-\mathrm{hPa}$ zonal wind; both are adaptations of Kang and Polvani (2011). This is an indirect measure of the zonal-mean subtropical jet position, required because direct measures are problematic in separating the subtropical from 


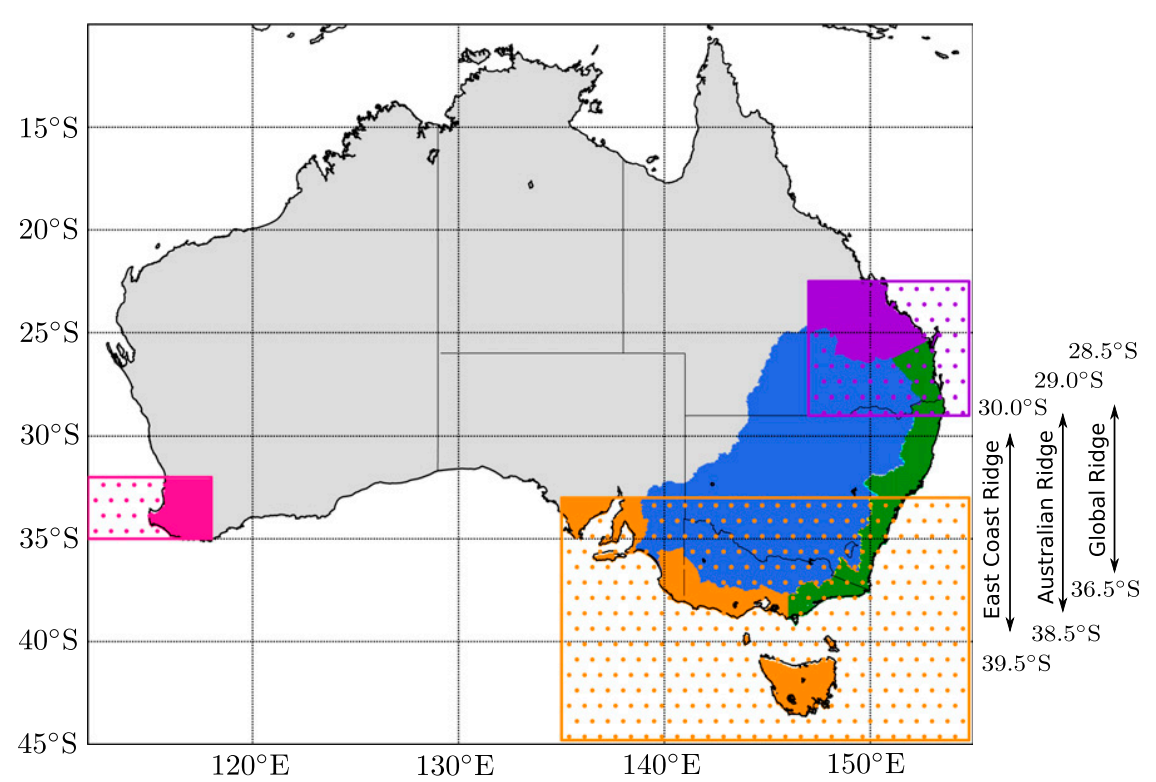

FIG. 1. Five regions of interest include SWWA (pink), SEA (orange), SEQ (purple), MDB (blue), and ENSW (green). The east, Australian, and global ridge domains are plotted to the right of the map. The minimum and maximum latitudes correspond to the approximate range of monthly mean latitudes over each ridge domain. For the subtropical ridge life cycle in ERAInterim, see Fig. 2 of MS14. This map is adapted from MS14.

the eddy-driven jet (see MS14 for more details). As such, the subtropical jet position should be interpreted as the zonal-mean subtropical jet position.

The ridge intensity is measured by the maximum of a cubic spline fit to the zonal mean sea level pressure, and the latitude of the maximum defines the ridge position; this method has also been used previously by Larsen and Nicholls (2009) and Cai et al. (2011a). The ridge intensity and position are sensitive to the longitudinal domain over which they are calculated. In this study three domains are used: along the east coast of Australia $\left(145^{\circ}-150^{\circ} \mathrm{E}\right)$, across the breadth of Australia $\left(110^{\circ}-\right.$ $155^{\circ} \mathrm{E}$ ), and globally (all longitudes), herein referred to as the east, Australian, and global domains, respectively.

Observed variability indices are calculated using monthly mean ERA-Interim reanalysis (Dee et al. 2011) from the European Centre for Medium-Range Weather Forecasts (ECMWF) for the same 30-yr time period as the AWAP precipitation data (1979-2008). As with the precipitation time series, the seasonal cycle and then linear trend are removed from the time series. Each time series is then normalized to unit variance.

\section{c. CMIP models}

Because of the intensive nature of the model diagnostics used in this study, we do not analyze the complete set of CMIP multimodel ensemble of climate models, but focus on what we propose is a representative sample of them.
Data from four CMIP models are analyzed: HadGEM1 and HadGEM2-ES, INM-CM3.0 and INM-CM4.0, CCSM3 and CCSM4, and ACCESS1.0. The modeling group, CMIP phase, and resolution are given for each model in Table 1. The models selected were somewhat arbitrary. The Australian ACCESS1.0 model was selected because it is most relevant to the Australian region. ACCESS is not an independent model, as the atmospheric and land models are the same as HadGEM2-ES, but the ocean model is different (Bi et al. 2013). Because of their similarities HadGEM2-ES was selected in this study, as differences in their response could identify sensitivities. CCSM4 was selected as it, like HadGEM2-ES, captures both ENSO (Bellenger et al. 2014) and SAM (Miller et al. 2006), and it is a widely studied model. INM-CM4.0 was selected as it uses a less commonly used relaxation convection scheme.

Each of the four CMIP5 models has small summer and winter precipitation biases over Australia; CCSM overestimates summer precipitation, but this is consistent with other CMIP5 models (see Liu et al. 2014, their Fig. 5). No attempt is made to correct for mean-state biases in the model, for example, the latitude of the Hadley cell edge, which may cause modeled relationships to respond differently.

Indices are derived from the first historical run of CMIP5 (r1i1p1), used for the 2013 IPCC report (Taylor et al. 2012), and the first historical run of CMIP3 (20C3M), used for the 2007 IPCC report (Meehl et al. 
TABLE 1. Resolution of ERA-Interim and CMIP models.

\begin{tabular}{llll}
\hline \multicolumn{1}{c}{ Modeling group } & Model name & CMIP & Model resolution \\
\hline ECMWF & ERA-Interim & $1.5^{\circ} \times 1.5^{\circ}$ & $1.975^{\circ} \times 1.25^{\circ}(\mathrm{N} 96)$ \\
Hadley Centre for Climate Prediction & HadGEM2-ES & CMIP5 & N96 \\
& HadGEM1 & CMIP3 & N96 \\
Australian Community Climate and Earth-System Simulator & ACCESS1.0 & CMIP5 & $1.5^{\circ} \times 2^{\circ}$ \\
Institute for Numerical Mathematics & INM-CM4.0 & CMIP5 & $5^{\circ} \times 4^{\circ}$ \\
& INM-CM3.0 & CMIP3 & CMIP5 \\
Community Climate System Model & CCSM4 & CMIP3 & $1.4^{\circ} \times 1.4^{\circ}$ \\
\hline
\end{tabular}

2007), for the 30-yr period from 1969 to 1998 . This time period is one decade earlier than observations because of the termination date of CMIP historical runs, but includes essentially the same external forcings (e.g., the El Chichón and Pinatubo volcanic eruptions plus slowly changing greenhouse gases and aerosols) and so should yield essentially the same results as the slightly later period.

\section{d. Preliminary evaluation of model variability}

Previous studies have found that models reproduce the modes of variability reasonably well, although the skill varies between models. The representation of ENSO has improved in CMIP5 relative to CMIP3, in particular the spatial pattern, amplitude, and life cycle (Kim and Yu 2012; Bellenger et al. 2014). However, problems still exist with the double ITCZ, cold tongue bias, and underestimation of wind-SST and shortwaveSST feedbacks (Bellenger et al. 2014; Li and Xie 2014). The SAM's spatial pattern has improved in CMIP5, but the variance explained by the SAM is still too large and models overestimate the time series amplitude (Miller et al. 2006; Zheng et al. 2013). The IOD is present in CMIP5 models but not improved since CMIP3, and it still produces a too-large IOD amplitude (Weller and Cai 2013). CMIP3 models have a realistic subtropical ridge annual cycle (Kent et al. 2013) and incremental improvements occurred in the ridge annual cycle for CMIP5 models (Grose et al. 2015). However, in general, both model generations fail to reproduce the spatial correlation between the ridge intensity and annual precipitation in SEA (Grose et al. 2015; Kent et al. 2013).

The ability of each model to reproduce each variability index is tested by comparing the time series of model-simulated and reanalysis-derived index values before normalizing (not shown). Each model roughly captures the amplitudes of ENSO and IOD, although models generally produce a weaker-than-observed SOI and stronger-than-observed DMI time series consistent with the above studies. Similar standard deviations were found for both the reanalysis and model-simulated variability for blocking, the intensity, and position of the subtropical jet and ridge.

The simulated SAM spatial pattern (the first empirical orthogonal function) is similar in each model to observations. Furthermore, the percentage of variance explained by the SAM is similar to the reanalysis value of $28.4 \%$, ranging for CMIP5 models from $23.1 \%$ to $28.3 \%$, and for CMIP3 models from $20.2 \%$ to $30.6 \%$.

In summary, each of the climate models examined reasonably reproduced each of the variability indices. Thus, there does not appear to be any reason to reject any of these models on the basis of their simulations of these univariate indices. We thus proceed to examine the interrelationships between these indices.

\section{$e$. The multivariate linear independence model}

The multivariate linear independence model uses multiple linear regression, following Sherwood (1999), to determine the partial correlations and conditional independence between the variability indices and precipitation in each region. Iteratively zeroing out nonsignificant partial correlations and refitting the model removes the tendency to overfit data, which would otherwise be a serious problem in a general multivariate Gaussian model with a modest sample size. Such zeroes are interpreted as conditionally independent links: an index A is independent of index B given all other indices, that is, no new information is given by $\mathrm{A}$ to explain $\mathrm{B}$ (and vice versa) once the remaining variables are known (MS14).

Validation of the technique in this context was performed in MS14 by comparing literature to traditional correlations and partial correlations. The independence model is traditionally presented as a chain graph; however, because of the large number of fitted models, the results are presented in the more compact partial correlation matrix plots. The independence model is sensitive to the significance threshold used; significance thresholds of $90 \%$ and $95 \%$ are used in this study. 


\section{f. Skill score metric}

The Peirce skill score (PSS) in Eq. (1) is used to describe the skill of each CMIP model in reproducing the observed relationships between ERA-Interim and AWAP determined by the multivariate linear independence model. The PSS was first proposed by Peirce (1884), although it is also known as the HanssenKuipers discriminant and the true skill statistic. The PSS is the difference between the hit rate $(H)$ and the false alarm rate $(F)$ (Wilks 2011, p. 312):

$$
\mathrm{PSS}=H-F=\frac{a d-b c}{(a+c)(b+d)} .
$$

A model that perfectly describes the observed interactions would have a skill score of one.

"Hits" $(a)$ is the number of partial correlations found in both observations and models at the $90 \%$ threshold for the multivariate linear independence model. "Correct rejections" $(d)$ is the number of links absent in both observations and model at the $90 \%$ threshold, herein conditionally independent. "False alarms" $(b)$ is the number of model links found at the $95 \%$ threshold and absent in observations at the $90 \%$ threshold. The reverse occurs for the number of "misses" $(c)$, observed partial correlations at $95 \%$ not found in the models at $90 \%$. The stricter significance threshold used to identify false or missed relationships is intended to minimize contamination of scores by false detections. If the $90 \%$ threshold were used in both cases it would imply models need to identify weak and less reliable signals in the observations and could excessively penalize models that fail to do so. The components of Eq. (1) are herein referred to as skill components.

All other paired combinations not accounted for are considered "inconclusive," such as differences in the sign of a link (this occurs infrequently) or when a link is detected at $90 \%$ (but not $95 \%$ ) in a model and is absent in observations (or vice versa). Inconclusive links do not contribute to the skill score but reflect links that are neither conditionally independent nor significantly partially correlated.

Skill scores are computed for each ridge domain in each season, summed to give a seasonal skill score for all ridge domains or summed to give the annual skill score. Error bars are calculated by bootstrapping using 100 samples with replacement to create a distribution of random 30-yr time series for each index. These distributions are then run through the linear independence model to compute 100 random partial correlation matrices. For each skill component, within each ridge domain, $\pm 2 \sigma$ is used as the upper and lower error bounds. The error for the seasonal and annual sums of the skill components are calculated by adding component errors in quadrature. The error in the skill scores in Eq. (2) are computed by the total derivative of the skill in Eq. (1):

$$
d \mathrm{PSS}=\frac{\partial \mathrm{PSS}}{\partial a} d a+\frac{\partial \mathrm{PSS}}{\partial b} d b+\frac{\partial \mathrm{PSS}}{\partial c} d c+\frac{\partial \mathrm{PSS}}{\partial d} d d .
$$

Each models' resolution is broadly similar to the resolution of ERA-Interim. Nonetheless, to test whether data resolution directly influences skill scores, the observed indices were calculated using both the native ERA-Interim grid and regridding ERA-Interim to the same resolution as each model. Differences in the skill are small. All results presented in this study are based on indices computed from data on the native ERAInterim grid.

Furthermore, to test the sensitivity of the subtropical jet intensity to the pressure level selected, the $200-\mathrm{hPa}$ subtropical jet intensity was also calculated and the multivariate linear independence model analysis repeated. Skill scores are similar whether the 200- or 250-hPa level is selected. Differences are generally within the error bars and hence noise. Results in sections 4 and 5 only describe robust results independent of the subtropical jet intensity level and the grid resolution of ERA-Interim.

\section{A review of the physical mechanisms connecting precipitation drivers}

The known Australian precipitation drivers were introduced in section 1. Here mechanisms discussed in the literature are described in more detail for comparison to the results in this study. The winter mechanisms are reviewed in section $3 \mathrm{a}$, as this season is of primary interest here and in the literature; the other seasons are reviewed in section $3 b$.

\section{a. Winter}

Precipitation variability has been the focus of many studies, especially in SEA during winter where drying trends are observed and multiple drivers influence precipitation. In this section we describe the interaction between the variability indices, their influence on precipitation in each region, and the physical mechanism by which they influence precipitation.

The positive SAM phase is associated with winter drying in SWWA and SEA because of decreased westerly flow that weakens the westward-moving synoptic weather systems (Hendon et al. 2007). The number of regions in which precipitation is directly influenced by SAM is limited compared to that for other precipitation drivers. When the influence of the ridge intensity is removed from the signal, the correlation only persists in 
SWWA. This SWWA precipitation correlation with SAM is not consistently reported (see, e.g., Fig. 12c of Risbey et al. 2011).

During winter the IOD and ENSO are weakly correlated ( $r=0.4$; see Fig. 1a of Cai et al. 2011b). The negative phases of IOD and La Niña both cause wetter conditions in winter in all regions of interest to this study except ENSW (Meyers et al. 2007; Ummenhofer et al. 2009). During the cool season, when IOD is active, moistening due to the negative IOD phase is associated with anomalously warm SSTs in the eastern Indian Ocean. The warm eastern-pole SSTs cause increased eastward moisture advection across northern and central Australia (Ummenhofer et al. 2009). During La Niña events, the Walker circulation is shifted to the west and the ascending branch of the circulation is closer to Australia. This promotes wetter conditions because of the anomalous vertical motion that enhances convection (BoM 2012).

When taking into account the IOD-ENSO correlation, ENSO dominates the precipitation variability in SEQ and northern MDB (see Fig. 6b of Risbey et al. 2009) and IOD dominates in SEA and southern MDB (Fig. 5b of Risbey et al. 2009). When the influence of the subtropical ridge intensity is removed, the winter precipitation signal associated with IOD is no longer significant in any of the regions (Fig. 4b of Cai et al. 2011a). ENSO is no longer significantly correlated with precipitation when the influence of the ridge intensity is removed (Fig. 9b of Cai et al. 2011a). The northern part of the MDB is affected by ENSO but not the whole basin. As such, neither ENSO nor IOD independently contribute to precipitation variability in any of the five regions considered in this study.

The tropical edge also influences Australian precipitation. A strong subtropical ridge (and, to a lesser extent, a poleward ridge) has previously been shown to cause drying in SEA, ENSW, and southern MDB (Cai et al. 2011a; Timbal and Drosdowsky 2012). The position and intensity of the ridge are highly correlated with one another and with IOD, SAM, and ENSO (Drosdowsky 2005; Williams and Stone 2009; Cai et al. 2011a). In southwest SEA, Whan et al. (2014) showed that the ridge intensity dominates the drying response, compared to its position, in winter and autumn when both linear and nonlinear techniques were applied. The influence of the ridge intensity (east ridge domain) persists in SEA and MDB (but not ENSW) when the influences of the ridge position, IOD, and SAM are each statistically removed (Cai et al. 2011a).

ENSO, SAM, and IOD each interact with the ridge in unique ways. La Niña is linked to a weak ridge; however, their correlation is small in winter. During the positive
SAM phase the westerly winds are contracted, and this is associated with a poleward and strong ridge (Cai et al. 2011a). The ridge interacts with the IOD via Rossby wave trains. Cool SST anomalies in the eastern Indian Ocean (positive IOD) suppress local convection, creating vertical motion and divergence anomalies that excite an equivalent-barotropic Rossby wave train propagating eastward and poleward (Hoskins and Karoly 1981; Cai et al. 2011a). The wave train changes the mean state westerlies, baroclinicity, west-east steering of upstream storms, and produces a high-pressure center south of Australia that suppresses precipitation in SEA (Cai et al. 2011b). The high-pressure center associated with IOD is located near the annual mean east ridge latitude that is also positioned within the MDB region and just north of SEA. This high-pressure center interacts with the subtropical ridge, which is also stronger when located poleward, thus preventing westerly midlatitude weather systems from bringing rain to southern Australia (Larsen and Nicholls 2009).

Strong atmospheric blocking causes wetter conditions in SEA and MDB (Pook et al. 2013; Cowan et al. 2013, along the $140^{\circ}$ meridian). Blocking is correlated with La Niña; negative IOD phase; and, to a lesser extent, a positive SAM (Cowan et al. 2013). During blocking events a surface anticylone impedes the flow, locally separating the subtropical and eddy-driven jets. When blocking occurs it is often associated with cutoff low-pressure systems (Risbey et al. 2009) or circulation anomalies that deliver moisture and precipitation from the tropics by cyclonic systems that form in association with La Niña (Cowan et al. 2013).

The direct influence of the subtropical jet on Australian precipitation is more uncertain because of limited studies on this topic. One exception is Frederiksen and Frederiksen (2007), who link SWWA drying to weakening of the subtropical jet and poleward-shifted circulation.

\section{b. Other seasons}

As in winter, the positive SAM phase is linked to drying in SWWA during autumn (Hendon et al. 2007). Conversely in summer, the positive phase of SAM brings wetter conditions to MDB, northern SEA, and ENSW (Hendon et al. 2007). The strongest precipitation response due to SAM occurs in spring where precipitation is correlated with SAM in northern SEA, MDB, ENSW, and SEA (Cowan et al. 2013). However, the regions affected vary between studies [see, e.g., Fig. 12d of Risbey et al. (2011) or Fig. 3 of Hendon et al. (2007)]. The wetter conditions in the east of the country are due to easterly wind anomalies promoting moisture advection from the Tasman Sea (Hendon et al. 2007). When the influence of blocking is removed from the 
SAM signal, springtime correlations with SAM remain significant only in SEQ (see Cowan et al. 2013, their Fig. 6, right panel).

Both IOD and ENSO influence Australian precipitation during winter (described in section 3a) and spring (Cai et al. 2011b). In spring, the ENSO-IOD correlation is much stronger than in winter (0.72 compared to 0.41; Cai et al. 2011b). During spring, the negative IOD phase causes wetter conditions in SWWA, SEA, and MDB (Cai et al. 2011a). When the intensity of the ridge is removed, IOD's influence remains in SWWA and MDB (the MDB signal is confined in the east along the great dividing range; Cai et al. 2011a).

During spring the influence of ENSO on precipitation in each region is similar to winter (see Figs. $2 \mathrm{c}$ and $2 \mathrm{~d}$ of Risbey et al. 2009). When the influence of IOD is removed, the correlations are not significant in any region (Fig. 6f of Cai et al. 2011b). ENSO's influence in summer occurs in SWWA, ENSW, SEQ, and to a limited extent in MDB (see Figs. 2a and 2b of Risbey et al. 2009). When taking into account the asymmetries of ENSO, La Niña causes wetter conditions in eastern SEQ and western MDB (see Fig. 5a of Cai et al. 2010). In autumn no region of interest to this study is affected by ENSO (Figs. 2a and 2b of Risbey et al. 2009).

During spring and autumn a strong ridge and, to a lesser extent, a poleward ridge cause drier conditions in SEA, SWWA (spring only), and southern MDB (Timbal and Drosdowsky 2012). In autumn the ridge position separates winter-like and summer-like conditions (Whan et al. 2014). During spring, the influence of the ridge intensity persists when the ridge position is removed (Cai et al. 2011a). In ENSW both the position and intensity of the ridge influence spring precipitation, but when IOD is removed the spatial extent reduces (Cai et al. 2011a). In summer a strong ridge causes wetter conditions in central MDB and drier conditions in southern SEA (Timbal and Drosdowsky 2012).

Atmospheric blocking has the largest impact on Australian precipitation during spring, bringing wetter conditions to SEA, southern ENSW, SEQ, and MDB (Pook et al. 2013). Spring blocking is associated with the positive SAM phase where spring mean SLP is stronger and more zonal compared to winter (Cowan et al. 2013). When the influence of SAM is removed from the spring blocking signal, correlations with the blocking only remain significant in ENSW (Fig. 6, right panel, of Cowan et al. 2013). In summer and autumn the influence of blocking is much weaker than spring, blocking influencing precipitation in SEA (only in autumn) and ENSW [see Pook et al. (2013, their Fig. 15) for $140^{\circ}$ blocking].

\section{Precipitation skill}

In Fig. 2 the winter partial correlations determined using the multivariate linear independence model are shown for observations (using ERA-Interim-derived variability indices and AWAP precipitation) and CMIP5 models. The partial correlation matrices for all other seasons and CMIP3 models are found in the online supplementary material (see Figs. S1-S7). In section 4a the skill of CMIP5 models to reproduce the observed precipitation variability in Australia is assessed, and section $4 \mathrm{~b}$ the CMIP5 skill is compared to the previousgeneration CMIP3.

\section{a. CMIP5 models}

The seasonal and annual skill scores are shown in Fig. 3 for the variability indices and precipitation. The CMIP5 models examined here successfully represent annual relationships between variability indices (capturing $>50 \%$ of possible variability hits) and their influence on precipitation ( $>45 \%$ of the possible precipitation hits). However, there is a large number of false alarms and missed links for both the variability and precipitation skill scores.

HadGEM and ACCESS share very similar atmospheric models, so it is not surprising they have similar skill scores. However, it is interesting that while the annual variability skill scores for these two models are larger than INM and CCSM, the annual precipitation skill scores are similar for all four models. Precipitation skills for three of the models are not significantly different, while ACCESS has a lower skill score.

Skill scores vary with season, but not in a robust way across the subset of CMIP5 models. In winter the variability skill scores are larger than the precipitation skill scores in each model (significantly larger in three models), while in other seasons there is no clear difference between the variability and precipitation skill scores. The magnitude of the precipitation skill scores are in general larger in summer than in other seasons.

Three model-specific problems with precipitation are identified in Fig. 3. First, INM has more precipitation false alarms than any other model, occurring mainly in winter associated with interactions with IOD and subtropical jet intensity (see Figs. 2g-i). Second, while the number of precipitation hits is smaller during summer, CCSM only has one hit resulting in a near-zero precipitation skill score. Third, HadGEM and ACCESS have less than half the number of precipitation hits as other models during autumn. During this season, ACCESS has a number of false alarms involving the subtropical ridge, but only in the east ridge domain (see Fig. S3). Furthermore, both HadGEM and ACCESS 

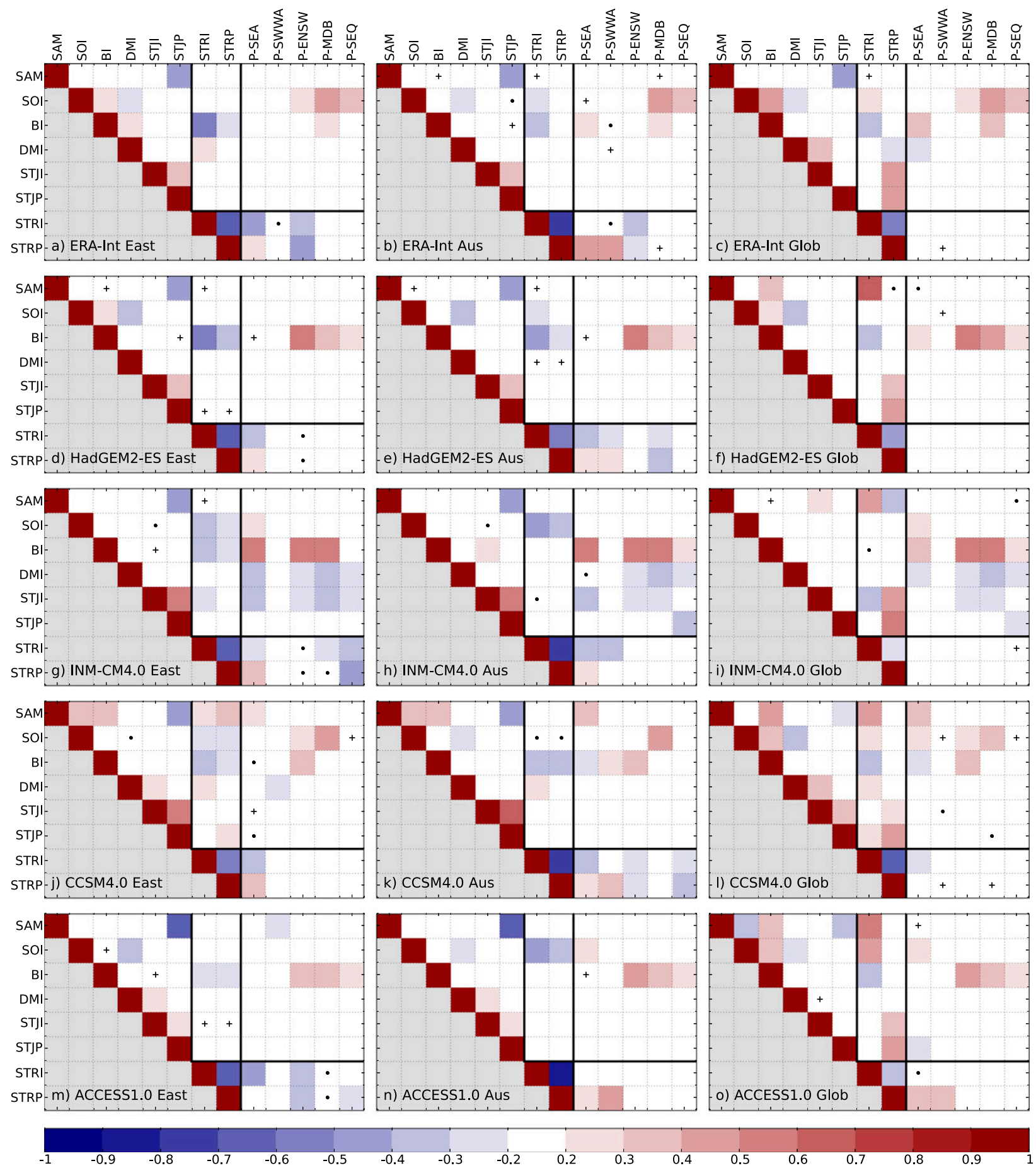

FIG. 2. Winter (June-August) partial correlation matrices from the multivariate linear independence model. Each subplot from the left to the right is for the east coast (East), Australian (Aus), and global (Glob) ridge domains. From top to bottom are ERA-Interim (originally published in MS14), HadGEM, INM, CCSM, and ACCESS for CMIP5. Red (blue) squares correspond to positive (negative) partial correlations with a $95 \%$ significance threshold and positive (negative) partial correlations with a $90 \%$ significance threshold shown with the $+($.$) symbol. White squares without either marker are conditionally independent. Solid black lines separate the variability [SAM,$ SOI, BI, DMI, subtropical jet position (STJP) and intensity (STJI)], ridge [position (STRP) and intensity (STRI)], and precipitation partial correlations in the five regions (P-SEA, P-SWWA, P-ENSW, P-MDB, P-SEQ). Other seasons are found in the supplementary material in Figs. S1-S3 and for CMIP3 models in Figs. S4-S7. 

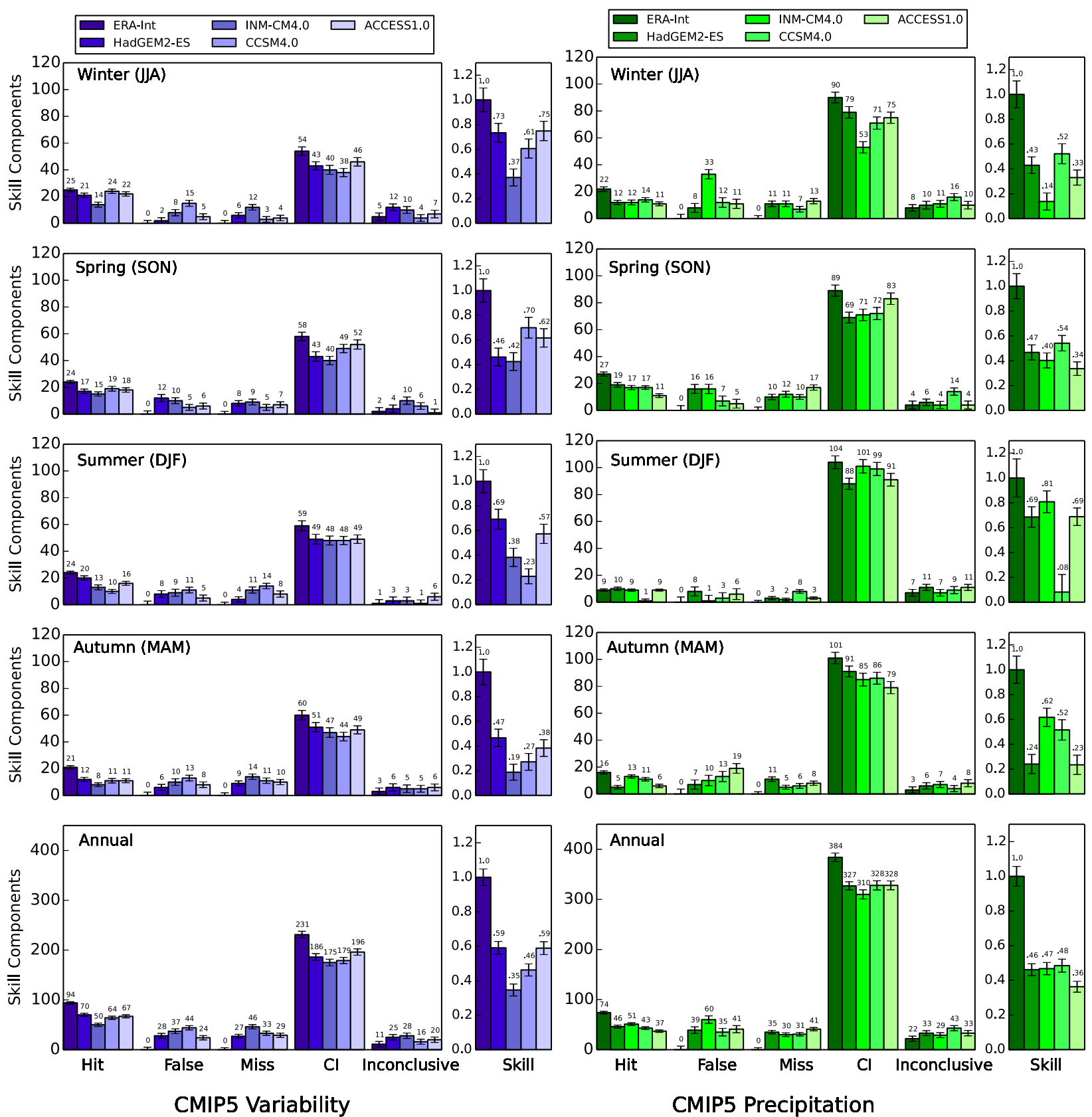

FIG. 3. Seasonal and annual PSSs for CMIP5 models. The two left columns (blue bars) are the interactions between variability indices, and the right two columns (green bars) are the influence of the variability indices on Australian precipitation. Each seasonal subplot is the sum of the skill components of each ridge domain. The annual subplots are the sum of the seasonal skill components. The seasonal and annual skill scores are calculated using the skill components [hit, false, miss, and conditionally independent pairs (CI)] seen in Eq. (1). Error bars correspond to $\pm 2 \sigma$.

miss every link involving ENSO during autumn. Capturing the drying due to El Niño is a general problem for this subset of CMIP5 models. The influence of ENSO on precipitation is only represented in some regions in CCSM during winter and autumn (global domain only), and INM during autumn.
In summary, CMIP5 models are skillful in representing links between variability indices and their influence on precipitation. However, a large number of missed links and false alarms suggests that problems still exist. Interestingly, models with better variability skill are not more skillful in representing precipitation, suggesting 

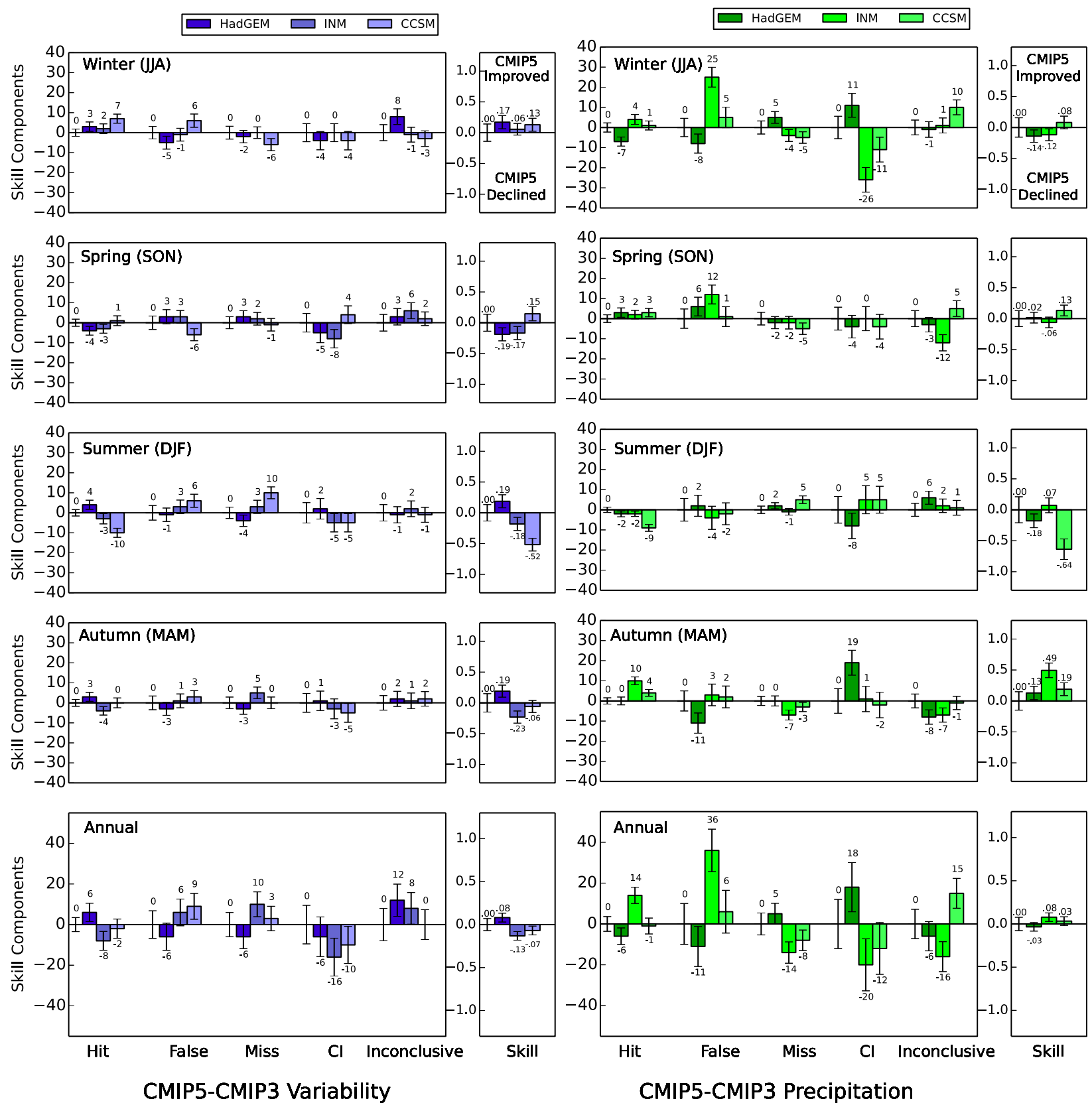

FIG. 4. As in Fig. 3, but for the difference between CMIP5 and CMIP3. Positive skill scores correspond to improvements in CMIP5.

that modeled precipitation drivers are not directly influencing precipitation skill. Three model-specific precipitation problems are identified that, if corrected, would likely improve precipitation in the respective models.

\section{b. Improvement from CMIP3 to CMIP5}

The differences in skill between CMIP3 and CMIP5 are shown in Fig. 4. CMIP5 models did not systematically improve in variability or precipitation skill; rather, each model responded differently between the model releases.
HadGEM annual variability skill had a small improvement in CMIP5, the result of improvements in each season except spring. This improvement is not robust when the 200-hPa level subtropical jet intensity is considered where more false alarms in winter result in no change between CMIP5 and CMIP3. HadGEM annual precipitation skill did not change in CMIP5. The skill declined in summer because of fewer conditionally independent pairs and in winter because of fewer hits primarily involving ENSO. Improvements occurred in 
autumn because of a reduction in false alarms and an increase in conditionally independent pairs.

INM annual variability skill had a small reduction in CMIP5. This decline is robust in spring because of fewer conditionally independent links. The summer variability skill also decreased; however, this is not robust as it not found when ERA-Interim is regridded to the resolution of INM, and as such, the summer skill is less certain. Despite a small reduction in annual variability skill, the annual precipitation skill improved in INM. This improvement is due to a large increase in autumn precipitation hits, primarily involving ENSO. This improvement would be greater if the precipitation false alarms had not increased as well in CMIP5 (involving IOD and subtropical jet intensity during winter). The decrease in variability skill and increase in precipitation skill suggests that precipitation in this model is more sensitive to the grid-scale resolution than variability skill scores, where the grid increased from $5^{\circ} \times 4^{\circ}$ in CMIP3 to $1.5^{\circ} \times 2^{\circ}$ in CMIP5.

CCSM annual variability skill did not change; a small decrease is seen, but this is not robust as it is not found when using regridded ERA-Interim data. In summer, a large reduction in skill occurs but is balanced by smaller improvements in winter and spring. The summer reduction is because of fewer hits and more misses (both involving SAM, ridge, or subtropical jet) and more false alarms. The annual precipitation skill of CCSM did not change either: in summer the precipitation skill considerably decreased, while small robust improvements occurred in spring and autumn. The summer skill decrease is because of fewer hits in CMIP5, and CMIP3 is more skillful in reproducing the influence of blocking on precipitation.

Previous studies have shown that the representation of ENSO has improved in CMIP5 generation models. In winter, the ENSO precipitation response is closer to observations in CMIP3 for HadGEM, very similar for INM, and for CCSM is closer to observations in CMIP5 (see Fig. 2 and Fig. S4). In spring, the observed ENSO precipitation response is not captured by any model in either CMIP generation. In summer, the observed influence of ENSO on precipitation is weak. CCSM has corrected a false alarm in CMIP3 between ENSO and summer SWWA precipitation. In HadGEM a summer false alarm with ENSO and MDB precipitation in CMIP3 has been corrected in CMIP5 but a new false alarm occurs with SWWA precipitation and ENSO. In autumn, the CMIP5 versions of INM and CCSM have both improved in representing the influence of ENSO on precipitation where previous generations had no links with ENSO.

Previous studies have shown that SAM's spatial pattern has improved in CMIP5; however, as SAM does not influence precipitation in any region or season in observations, only false alarms with the SAM can be identified in CMIP5 and CMIP3, which are more common in winter and spring.

Previous studies have shown no improvement in the representation of IOD. The only observed direct influence of IOD on precipitation occurs in SEA during winter and spring. CCSM has improved by linking IOD to spring precipitation in SEA, although it now also influences SWWA (not seen in observations). INM has also improved in linking IOD to winter and spring precipitation in SEA; however, it covers a broader spatial area linked in four of the five regions. The observed ENSO-IOD link during winter and spring is now found in CCSM4 but not the previous generation in either season. This link is also found in HadGEM for winter in both CMIP versions but not in spring. The IOD-ENSO link is missing in both INM versions in both seasons.

In summary, some seasonal improvements are found in CMIP5, but no systematic improvement in variability skill or precipitation is found in CMIP5 compared to CMIP3. Small improvements have occurred in the modeled interactions between ENSO and IOD and the influence of IOD on Australian precipitation. The influence of ENSO on Australian precipitation remains poorly represented.

In section 1, two questions were posed, the first being "Is modeled Australian precipitation skillful?" We find that models are skillful in representing the relationships between variability indices and precipitation in CMIP5; however, no robust improvements in variability or precipitation skill occur in CMIP5 compared to the previous-generation CMIP3 models.

\section{Seasonal precipitation responses to the tropical edge}

The Hadley cell edge has expanded in recent decades and is expected to continue its expansion in the future. Changes in the width of the Hadley cell are an aspect of particular interest for climate change that has received less attention than other precipitation drivers. In this section we focus on how a poleward-located Hadley cell edge influences Australian precipitation in the context of natural variability.

Tropical edge metrics have been shown to influence precipitation directly and indirectly via interactions with IOD or blocking (MS14). Often multiple pathways or mechanisms influence precipitation in each region, with opposing drying and moistening mechanisms resulting in an ambiguous net precipitation response.

The Australian precipitation response to poleward tropical edge is exhibited graphically in Fig. 5 for all seasons in observations (left panels of Fig. 5 are described in section 5a) and CMIP5 models (right panels of Fig. 5 are described in section $5 b$ ). 
Precipitation response to a poleward located Hadley cell edge
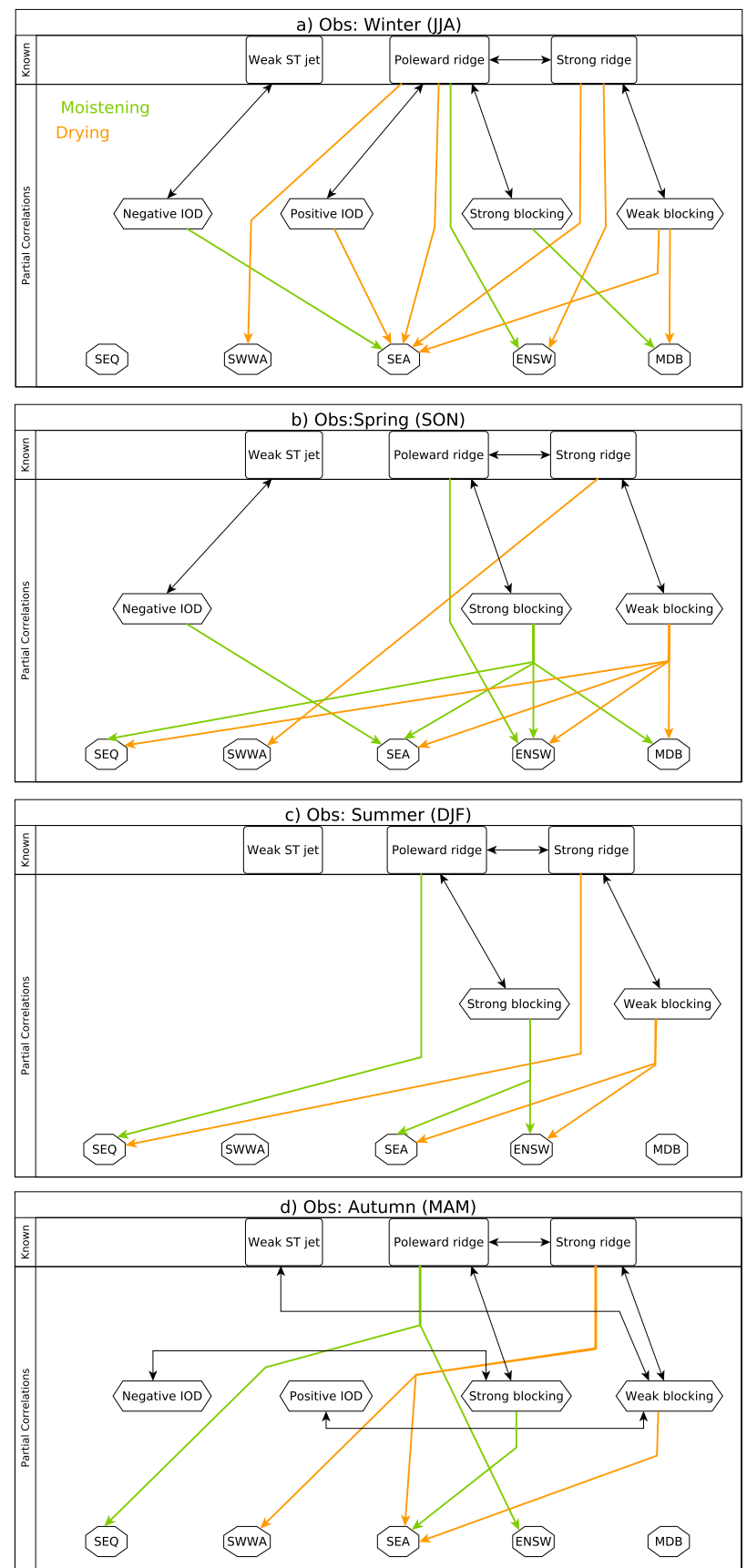

Modeled precipitation response to a poleward located Hadley cell edge
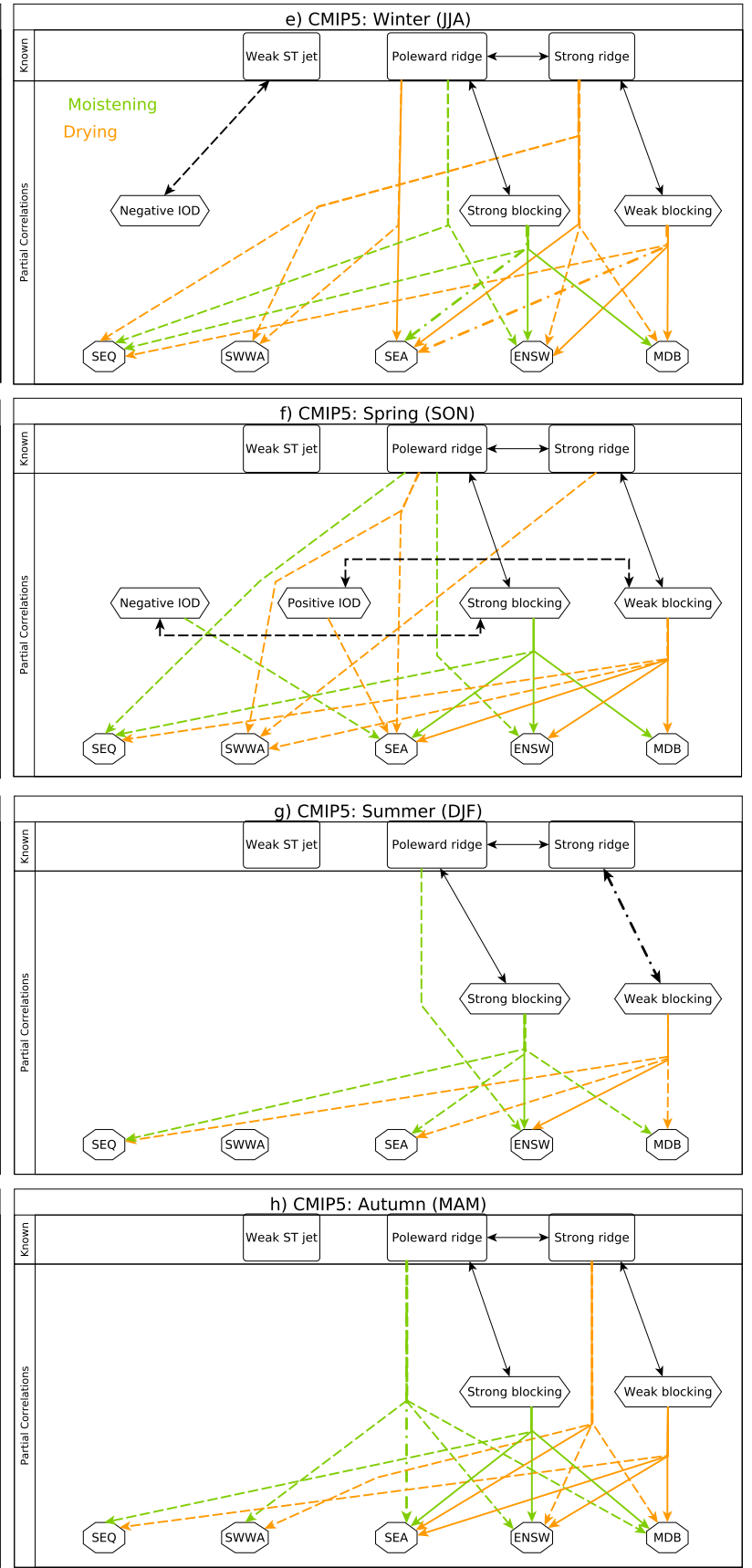

FIG. 5. Summary of the seasonal precipitation dependencies to a poleward-located Hadley cell in (left) observations and (right) CMIP5 models. Black lines join variability indices (not causal linked). Green (orange) lines link variability indices that cause moistening (drying). Solid (dashed) lines for CMIP5 model subplots indicate that each (at least half) of the models agree on the sign of the relationship and dash-dotted lines when the sign is different between models. This figure is based on the winter partial correlations in Fig. 2 and in other seasons in Figs. S1-S3. This figure considers all ridge domains using the 95\% significance threshold.

\section{a. Observed responses}

In section 3a the winter precipitation mechanisms were described. From these previous studies, we would independently expect winter drying, or visa versa, in the following regions: SEA, because of strong ridge and weak blocking; SWWA, because of poleward and weak subtropical jet; ENSW, none; 
MDB, because of strong ridge and weak blocking; and SEQ, none.

ENSO is not consistently partially correlated with the tropical edge metrics in Fig. 2, so the influence of ENSO on precipitation is not considered in this section. Furthermore, SAM does not influence precipitation in any region or season (see Fig. 2 and Figs. S1-S3). Given the lack of partial correlations with SAM, it is also excluded from the analysis in this section. However, we note that this is not always true in other studies, such as Cai et al. (2011a), who find that SAM interacts with SEA precipitation via the position and intensity of the ridge. Not all links found in the literature are expected in Fig. 5a as the influence of each driver is removed in this analysis, which is not the case for previous studies.

The influence of tropical edge metrics on precipitation during winter was previously shown by MS14 and reproduced here in Fig. 5a. Winter results are consistent with previous literature as noted by MS14. During winter, one moistening and four drying mechanisms were found to directly or indirectly influence precipitation in SEA resulting from a poleward-located Hadley cell edge.

In Fig. 5a a poleward and strong ridge directly causes drying in SEA and indirectly as a strong ridge is linked to weak blocking, consistent with Pook et al. (2013). Furthermore, a poleward ridge and weak subtropical jet are linked to opposite phases of IOD, resulting in opposing drying and moistening influences. Cai et al. (2011a) previously identified that the position and intensity of the ridge both influence precipitation in SEA, but not IOD after the influence of either ridge metric was removed. Cai et al. (2011a) concluded that IOD indirectly influences precipitation by inducing changes to the position and intensity of the ridge. We do not find a significant partial correlation between IOD and ridge intensity (except in the east ridge domain, however; the IOD is not linked to precipitation in this domain), suggesting a mechanism involving the intensification of the subtropical jet rather than the ridge. Because of the opposing moistening and drying influences, the net effect of IOD on precipitation in SEA due to a poleward-located Hadley cell is not clear.

In other regions, the influence of the Hadley cell edge latitude on winter precipitation is less complicated. A poleward subtropical ridge causes drying in SWWA. Timbal and Drosdowsky (2012) and Cai et al. (2011a) attribute this drying to the intensity of the ridge rather than its position, and this is weakly evident in Fig. 2 for the east ridge domain. The subtropical jet is not linked to precipitation variability in SWWA (Fig. 5a) in contrast to the conclusions of Frederiksen and Frederiksen (2007).

Opposing drying and moistening mechanisms influence ENSW because of a poleward and strong ridge (Fig. 5a). This was also seen by Cai et al. (2011a), who found that a strong ridge causes drying and a poleward ridge causes moistening, but when IOD and SAM were removed they found the ridge intensity no longer significantly influenced precipitation in ENSW. Presumably the same is true for a poleward ridge, but Cai et al. (2011a) only showed results for the ridge intensity because of the virtually identical but weaker in size responses for the ridge position. In Fig. 5a both the ridge intensity and position are significant. Neither link is found when traditional correlations are considered (Cai et al. 2011a; Timbal and Drosdowsky 2012).

Opposing drying and moistening mechanisms indirectly influence MDB via interactions with blocking. This is consistent with Timbal and Drosdowsky (2012) and Cai et al. (2011a), who find that ridge intensity (but not position) influences precipitation in MDB. Furthermore, it is consistent with Pook et al. (2013) and Cowan et al. (2013), who find that strong blocking causes wetter conditions in MDB. The net contribution of the ridge on precipitation in ENSW and MDB is uncertain as the influence of its position and intensity act in opposite directions. How important the interactions are between the ridge and blocking in influencing precipitation in MDB is also not clear as their links vary with the ridge domain (Figs. 2a-c).

In section $3 \mathrm{~b}$ the precipitation mechanisms for seasons other than winter were described. From these previous studies we would independently expect drying in the following regions: SEA, because of strong ridge (spring, autumn, summer) and weak blocking (autumn); SWWA, because of positive phase of IOD (spring) and strong ridge (spring); ENSW, because of weak blocking (autumn, spring) and equatorward and strong ridge (spring); MDB, because of positive phase of IOD (spring), strong ridge (spring, autumn) and weak ridge (summer), and $\mathrm{La}$ Niña (asymmetry in ENSO; wetter conditions in summer); and SEQ, because of SAM (spring) and La Niña (wetter conditions in summer).

Some of the observed winter partial correlations persist in spring (Fig. 5b). Moistening in SEA due to a weak subtropical jet via the negative IOD phase is consistent with Meyers et al. (2007), but somewhat unexpected given the limited area affected by IOD as seen in Cai et al. (2011a, their Fig. 7b). Moistening occurs in ENSW because of a poleward ridge and drying in SWWA because of a strong ridge (linked to a poleward ridge instead in winter), both consistent with Timbal and Drosdowsky (2012) and Cai et al. (2011a). Unlike winter, the spring subtropical ridge position is conditionally independent of IOD. This was seen previously by Cai et al. (2011a), who also find that the ridge intensity and IOD are correlated; however, in the present study the spring IOD is conditionally independent of the ridge intensity and position. 
In spring the influence of blocking on precipitation is broader than winter (see Figs. 5a,b), affecting each region except SWWA, which is geographically isolated from the other regions. Cowan et al. (2013) found that when the influence of SAM is removed from the blocking signal, the precipitation response is no longer significant in any region except ENSW. Strong blocking is linked to the positive SAM phase during spring (see Fig. S1), consistent with Cowan et al. (2013); however, the broad influence of blocking on precipitation persists after the influence of SAM (and all other metrics) is taken into account. In each region except ENSW, the opposing drying and moistening mechanisms are indirectly associated with a strong and poleward ridge via blocking. A strong ridge is linked to weak blocking in each ridge domain; however, blocking and the ridge position are not linked in all ridge domains. As such, it is not clear the extent to which the ridge uniquely contributes to precipitation variability and what can be attributed to blocking.

There are fewer precipitation links in summer than in other seasons (see Figs. 5a-d) also seen in the skill scores (see Fig. 3). During summer the Hadley cell edge is located at its most poleward extent in the seasonal cycle. Summertime precipitation in SEQ experiences opposing drying and moistening mechanisms due directly to a poleward and strong ridge. These links are significant with the Australian ridge domain and weakly significant ( $90 \%$ threshold) in the east ridge domain. Timbal and Drosdowsky (2012) previously found precipitation in SEQ to be independent of the ridge. These opposing mechanisms also indirectly influence summer precipitation in SEA and ENSW via interactions with blocking, previously found to be insignificant in SEA and weak in ENSW (Pook et al. 2013). It is not clear if the ridge indirectly contributes to precipitation variability in SEA and ENSW during summer, or if the interactions can be explained alone by blocking, as the ridge position and intensity only interact with blocking for some of the three ridge domains. When the $200-\mathrm{hPa}$ subtropical jet intensity index is used, a weak subtropical jet is linked to moistening in ENSW, but this link is not robust as it does not occur when the $250-\mathrm{hPa}$ subtropical jet intensity index is used.

In autumn there are more links between tropical edge metrics than in other seasons (see Fig. 5d). The IOD interacts with blocking, which in turn influences precipitation in SEA. Similarly to other seasons, the opposing drying and moistening mechanisms occur in SEA during autumn indirectly due to poleward and strong ridge via interactions with blocking, consistent with Risbey et al. (2009) and Pook et al. (2013). A strong ridge directly causes drying in SEA and SWWA, generally consistent with Timbal and Drosdowsky (2012) and Cai et al. (2011a). A poleward ridge directly causes moistening in SEQ and ENSW, consistent in ENSW with Cai et al. (2011a), but in SEQ it is inconsistent with Cai et al. (2011b) and Timbal and Drosdowsky (2012).

To summarize, the winter precipitation response using the multivariate linear independence model is generally consistent with previous studies, as noted previously by MS14. Two exceptions include conditional independence: SWWA winter precipitation with the subtropical jet and MDB winter precipitation with the ridge intensity. In other seasons, the results of this study differ more from previous studies. Over half of the expected links are found to be conditionally independent in this study. In each season a number of new links are identified, generally involving the subtropical ridge. The subtropical ridge is the only driver to influence Australian precipitation throughout the entire year, and it interacts both directly and indirectly via blocking. A strong seasonal dependence exists in the regions affected by the tropical edge metrics. The subtropical jet and IOD only influence precipitation during winter and spring. In each season opposing drying and moistening mechanisms complicate the net response in some regions as both are associated with a poleward-located Hadley cell. Further work is needed to identify how the domain used to identify the subtropical ridge changes the interpretation of how the subtropical ridge influences precipitation, especially in eastern Australia.

\section{b. CMIP5 models}

In each season the influence of the tropical edge on precipitation is generally well captured by the models, albeit with excessive links (false alarms). In winter, models successfully link a poleward ridge to drying in SEA and SWWA, a strong ridge to drying in SEA, and opposing drying and moistening to the ridge in ENSW. In spring, the models represent drying to a strong ridge in SWWA and moistening to a poleward ridge in ENSW. In autumn, models successfully link drying to a strong ridge in SEA and SWWA and moistening in ENSW and MDB (only in ACCESS) to a poleward ridge.

The opposing moistening and drying mechanisms due to blocking, ridge intensity, and ridge position occur in each season in observations and are well represented in CMIP5 models, albeit with excessive links. Links to blocking are also well captured in the models in each season, especially in spring. However, in each season blocking is linked to precipitation in more regions than is found in observations; hence, the spatial area affected by blocking is broader in models. Care should be taken 

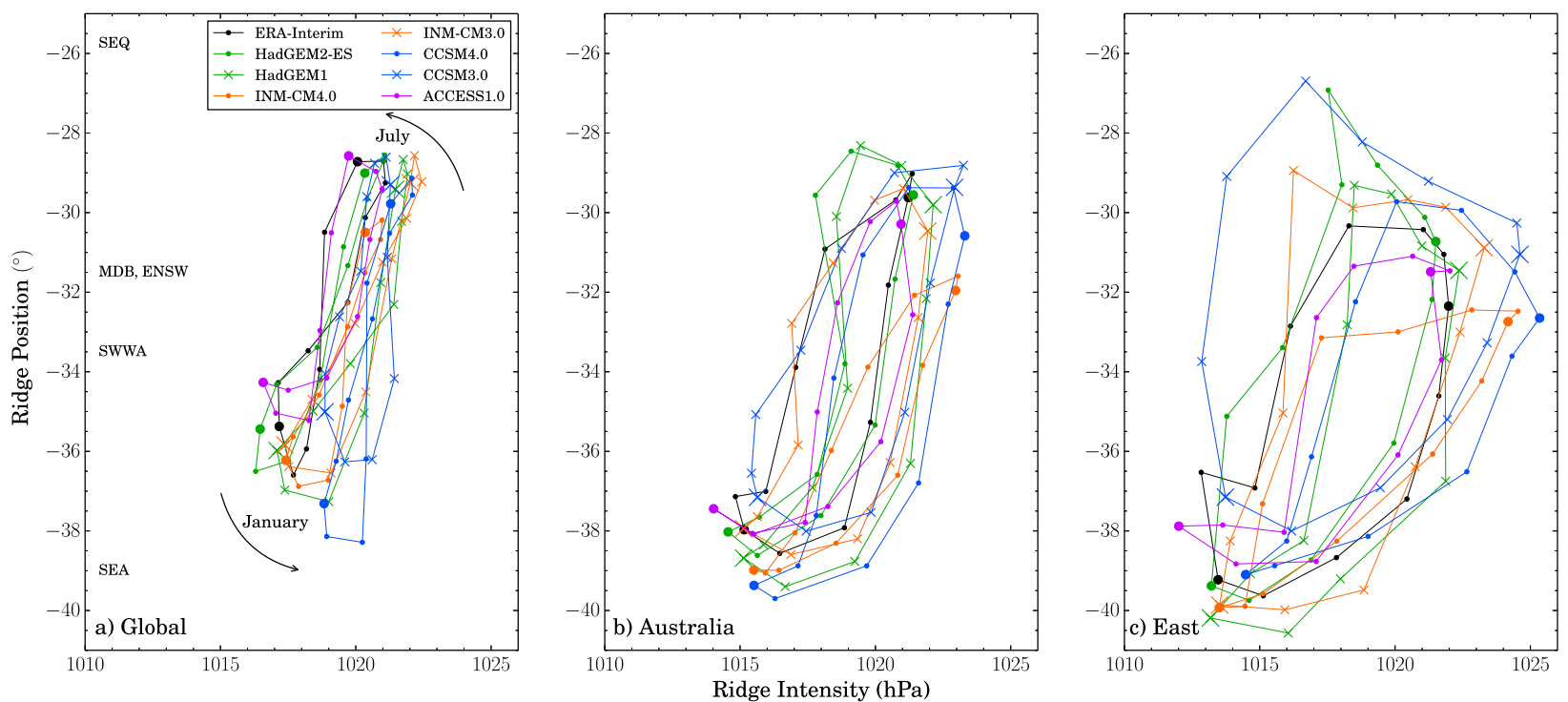

FIG. 6. The subtropical ridge life cycle for ERA-Interim and each model (circles for CMIP5 and crosses for CMIP3) for the three ridge domains: (a) global, all longitudes; (b) Australia, $110^{\circ}-155^{\circ} \mathrm{E}$; and (c) east, $145^{\circ}-150^{\circ} \mathrm{S}$. January (weaker and poleward) and July (stronger and equatorward) months have larger markers than other months, and arrows show the direction of monthly mean movement. The mean latitudes of the precipitation regions are annotated in (a) to identify the location of ridge in relation to the precipitation regions.

in interpreting the particular regions over which drivers influence precipitation in Fig. 5, as it is a representation of general model behavior and each link does not occur in each model in each season (see Fig. 2 and Figs. S1-S3).

The broader influence of blocking on precipitation in the models is not surprising, as an equatorward bias in the storm tracks exists in both CMIP3 and CMIP5 models in both hemispheres (Chang et al. 2012, 2013). In the Northern Hemisphere the storm tracks in CMIP5 models are too zonal (Zappa et al. 2013) and blocking is underestimated because of model mean state biases (Scaife et al. 2010).

Excessive links between the ridge and precipitation occur in each model, especially in autumn. To test if these excessive links are due to a bias in the mean position of the modeled ridge, the ridge life cycle for each model is plotted for the three ridge domains in Fig. 6 . The seasonal mean ridge position is reproduced reasonably well in each model, season, and domain. As such, the excessive links with the ridge are not due to a bias in the ridge position. The ridge life cycle is in general consistent with Grose et al. (2015) for CMIP5 and Kent et al. (2013) for CMIP3, bearing in mind that the ridge domain definitions are subtly different and that the time period and observed datasets are different. The seasonal-mean ridge position and intensity for each model are not statistically different to ERA-Interim. One notable difference (but not significant in the seasonal means) is that the CCSM3 east ridge domain is more equatorward compared to ERA-Interim and the other models.

There are a number of missing links in each model. First, IOD does not affect winter precipitation in SEA in any model, except INM; however, the IOD in this model has excessive links with precipitation. Second, autumn blocking is not linked to IOD in models, but is linked instead during spring. Third, the subtropical ridge is not linked in any model to SEQ summer precipitation or autumn in SEQ (except CCSM, which has excessive precipitation links with the ridge), but is linked instead via blocking in half the models.

Furthermore, there are two links where the sign of the relationship is inconsistent among the models. First, for winter SEA precipitation with blocking, CCSM identifies a negative partial correlation in each ridge domain while HadGEM and INM agree with the observed positive partial correlation. Second, for autumn precipitation in SEA with the ridge position, which not found in observations, CCSM identifies a negative link and ACCESS identifies a positive link.

Risbey et al. (2011) previously found that ACCESS successfully captured wintertime interactions between precipitation and blocking, but not with other sources of variability such as ENSO, SAM, or IOD. This is also seen in Figs. $2 \mathrm{~m}-\mathrm{O}$ and Fig. 5e; however, precipitation is not influenced by IOD (except in the global ridge domain in SEA) or SAM in winter. This study builds on Risbey et al. (2011) by including the subtropical ridge, which successfully interacts with precipitation in ACCESS. 
A number of model-specific improvements have occurred in CMIP5 compared to CMIP3 in linking the Hadley cell edge to precipitation variability. In winter, HadGEM links a poleward ridge to moistening in SEA and CCSM to opposing drying and moistening in ENSW due to a strong and poleward ridge. Furthermore, strong blocking is linked to moistening in SEA for HadGEM and INM. In autumn, strong blocking is linked to moistening in SEA for HadGEM. In spring and summer no improvements occurred.

There are also a number of missed links in CMIP5 that were hits in CMIP3. In winter, INM no longer links precipitation in SWWA to the ridge position. CCSM no longer links precipitation in MDB to blocking, and the SEA link with blocking now has the incorrect sign. In spring, INM no longer links precipitation in SWWA to the ridge intensity. In summer, INM no longer links precipitation in SEQ to the ridge position and CCSM no longer links SEA to blocking. In autumn, HadGEM no longer links precipitation in ENSW and SEQ to ridge position.

In summary, CMIP5 models are generally successful in reproducing the direct and indirect precipitation response in Australia to a poleward-located Hadley cell. However, the models are not consistent in the precipitation region affected by the subtropical ridge and tend to overestimate the spatial area affected, especially with blocking.

In the introduction two questions were posed, the second of which was "Can models simulate the influence of the tropical edge on Australian precipitation?" Models successfully represent many of the observed relationships with precipitation at the tropical edge; however, many excessive links occur that are not supported by observations. A strong seasonality exists in the influence of tropical edge metrics on Australian precipitation, which is to be expected and is consistent with previous studies.

\section{Conclusions}

The expansion of the tropics is likely to cause profound changes to precipitation in Australia. The scale and extent of the changes is currently uncertain, as there are many drivers that influence Australian precipitation and a number of known model shortcomings in reproducing regional precipitation. The physical mechanisms that control precipitation variability in Australia have been widely studied, and a reasonable understanding exists of how these mechanisms affect regional precipitation. No study has systematically evaluated these physical mechanisms in CMIP models and their affect on modeled precipitation in Australia. We offer a framework for doing this objectively using the multivariate linear independent approach. This approach takes into account covariability between drivers, does not overfit the data, and internally tests significance. The resulting partial correlation matrices can then easily be used to compute skill scores and identify model errors on comparison to observations.

The aim of this study is to assess model skill in reproducing observed Australian precipitation variability at the tropical edge. CMIP models are skillful in simulating the observed interactions between precipitation drivers, including tropical edge metrics, and their influence on Australian precipitation. However, CMIP5 models have not consistently improved compared to the previous-generation CMIP3 model in either of these aspects. CMIP models capture both the direct and indirect influence of a poleward-located Hadley cell on Australian precipitation; however, models are not consistent in the spatial area where precipitation is influenced by the subtropical ridge and overestimate the area where it is influenced by blocking in each season.

The net precipitation response in each region to a poleward-located Hadley cell is complicated by opposing mechanisms that vary seasonally. Models are not consistent in simulating Australian precipitation change in future scenarios, and it is likely that these unforced opposing mechanisms complicate this task further. Additionally, modeled precipitation skill is not systematically dependent on variability skill, suggesting that modeled precipitation does not respond correctly to large-scale flow patterns.

A number of model errors are identified that might help in tracing model errors. First, the influence of blocking on precipitation covers a greater spatial distribution in the models than is seen in the observations, although this is likely tied into the equatorward storm track bias. Second, strong blocking in winter causes moistening in SEA in observations and in each model except CCSM, which is linked to drying. Correcting this in CCSM may improve the representation of precipitation in this region. Third, INM shows many partial correlations linking precipitation to IOD and subtropical jet intensity that are not seen in the observations. Finally, ENSO does not influence precipitation to the extent that is seen in observations in any of these models in any season.

Improving these model biases, however, may not necessarily improve precipitation skill, as variability skill did not change proportionally with precipitation skill. For example, improved variability skill in HadGEM2.0-ES, compared to the earlier version, did not result in improved precipitation skill, nor did the reduction in variability skill for INM4.0 or CCSM4.0 result in a reduction in precipitation skill. This suggests that improving 
precipitation variability will require improvements to moist processes (or, potentially, land surface processes) regardless of improvement in the quality of representation of circulation drivers and their teleconnections.

There are a number of limitations in this study that have been taken into account when interpreting the results. The multivariate linear independent approach does not determine causality between linked variability indices. Furthermore, this approach only identifies linear relationships and is sensitive to the significance threshold used, and it is possible that direct links can be incorrectly identified if important proximate sources of variability are not included in the analysis or are poorly observed. See Maher and Sherwood (2014) for a full discussion of the limitations.

Two aspects of this study require further research. First, the covariability and controlling mechanisms between the subtropical jet, subtropical ridge, and SAM are briefly mentioned in this study and will be explored in a subsequent paper. Second, HadGEM and ACCESS are similar models, and differences in how drivers influence precipitation could be useful to identify the effect of changing model components on precipitation. Furthermore, HadGEM and ACCESS have similar precipitation skill to other models in this study but are more skillful in reproducing covariability of drivers. It would be beneficial to identify why improved variability is not translated into improved precipitation.

Acknowledgments. We thank Agata Imielska from the Bureau of Meteorology (BoM) for supplying the AWAP ocean and ENSW masks, and Dr. Kathryn Bormann for the Murray-Darling Basin mask. We acknowledge the BoM and CSIRO for providing the AWAP precipitation data. ECMWF ERA-Interim data used in this study were obtained from the ECMWF data server. We acknowledge the World Climate Research Programme's Working Group on Coupled Modelling, which is responsible for CMIP, and we thank the climate modeling groups (listed in Table 1 of this paper) for producing and making available their model output. We thank the two anonymous reviewers who improved the clarity of the manuscript. This work was supported by the Natural Environment Research Council Grant NE/M006123/1. We acknowledge the Australian Research Council (ARC) Grant FS100100054.

\section{REFERENCES}

Australian Academy of Science, 2015: The science of climate change: Questions and answers. Australian Academy of Science, accessed 13 January 2015. [Available online at www.science.org.au/ climatechange.]

Bellenger, H., E. Guilyardi, J. Leloup, M. Lengaigne, and J. Vialard, 2014: ENSO representation in climate models: From CMIP3 to CMIP5. Climate Dyn., 42, 1999-2018, doi:10.1007/ s00382-013-1783-z.

Bi, D., and Coauthors, 2013: The ACCESS coupled model: Description, control climate and evaluation. Aust. Meteor. Oceanogr. J., 63, 41-64.

BoM, 2012: Record-breaking La Niña events: An analysis of the La Niña life cycle and the impacts and significance of the 2010-11 and 2011-12 La Niña events in Australia. Bureau of Meteorology Tech. Rep., 24 pp.

Cai, W., and T. Cowan, 2013: Southeast Australia autumn rainfall reduction: A climate-change-induced poleward shift of oceanatmosphere circulation. J. Climate, 26, 189-205, doi:10.1175/ JCLI-D-12-00035.1.

_- A. Sullivan, and T. Cowan, 2009: Rainfall teleconnections with Indo-Pacific variability in the WCRP CMIP3 models. J. Climate, 22, 5046-5071, doi:10.1175/2009JCLI2694.1.

_- P. van Rensch, T. Cowan, and A. Sullivan, 2010: Asymmetry in ENSO teleconnection with regional rainfall, its multidecadal variability, and impact. J. Climate, 23, 4944-4955, doi:10.1175/2010JCLI3501.1.

,-- , and,$- 2011 \mathrm{a}$ : Influence of global-scale variability on the subtropical ridge over southeast Australia. J. Climate, 24, 6035-6053, doi:10.1175/2011JCLI4149.1.

,,,--- and H. H. Hendon, 2011b: Teleconnection pathways of ENSO and the IOD and the mechanisms for impacts on Australian rainfall. J. Climate, 24, 3910-3923, doi:10.1175/2011JCLI4129.1.

_ - T. Cowan, and M. Thatcher, 2012: Rainfall reductions over Southern Hemisphere semi-arid regions: The role of subtropical dry zone expansion. Sci. Rep., 2, 702, doi:10.1038/ srep00702.

Chang, E. K. M., Y. Guo, and X. Xia, 2012: CMIP5 multimodel ensemble projection of storm track change under global warming. J. Geophys. Res., 117, D23118, doi:10.1029/2012JD018578.

,,--- , and M. Zheng, 2013: Storm-track activity in IPCC AR4/CMIP3 model simulations. J. Climate, 26, 246-260, doi:10.1175/JCLI-D-11-00707.1.

Chou, C., J.-Y. Tu, and P.-H. Tan, 2007: Asymmetry of tropical precipitation change under global warming. Geophys. Res. Lett., 34, L17708, doi:10.1029/2007GL030327.

Collins, M., and Coauthors, 2013: Long-term climate change: Projections, commitments and irreversibility. Climate Change 2013: The Physical Science Basis, T. F. Stocker et al., Eds., Cambridge University Press, 1029-1136.

Cowan, T., P. van Rensch, A. Purich, and W. Cai, 2013: The association of tropical and extratropical climate modes to atmospheric blocking across southeastern Australia. J. Climate, 26, 7555-7569, doi:10.1175/JCLI-D-12-00781.1.

Dee, D. P., and Coauthors, 2011: The ERA-Interim reanalysis: configuration and performance of the data assimilation system. Quart. J. Roy. Meteor. Soc., 137, 553-597, doi:10.1002/ qj. 828 .

Drosdowsky, W., 2005: The latitude of the subtropical ridge over Eastern Australia: The $L$ index revisited. Int. J. Climatol., 25, 1291-1299, doi:10.1002/joc.1196.

Fierro, A. O., and L. M. Leslie, 2013: Links between central west Western Australian rainfall variability and large-scale climate drivers. J. Climate, 26, 2222-2246, doi:10.1175/JCLI-D-12-00129.1.

Frederiksen, J. S., and C. S. Frederiksen, 2007: Interdecadal changes in southern hemisphere winter storm track modes. Tellus, 59, 599-617, doi:10.1111/j.1600-0870.2007.00264.x.

Grose, M., B. Timbal, L. Wilson, J. Bathols, and D. Kent, 2015: The subtropical ridge in CMIP5 models, and implications for 
projections of rainfall in southeast Australia. Aust. Meteor. Oceanogr. J., 65, 90-106.

Held, I. M., and B. J. Soden, 2006: Robust responses of the hydrological cycle to global warming. J. Climate, 19, 5686-5699, doi:10.1175/JCLI3990.1.

Hendon, H. H., D. W. J. Thompson, and M. C. Wheeler, 2007: Australian rainfall and surface temperature variations associated with the Southern Hemisphere annular mode. J. Climate, 20, 2452-2467, doi:10.1175/JCLI4134.1.

Hope, P., W. Drosdowsky, and N. Nicholls, 2006: Shifts in the synoptic systems influencing southwest Western Australia. Climate Dyn., 26, 751-764, doi:10.1007/s00382-006-0115-y.

Hoskins, B. J., and D. J. Karoly, 1981: The steady linear response of a spherical atmosphere to thermal and orographic forcing. J. Atmos. Sci., 38, 1179-1196, doi:10.1175/ 1520-0469(1981)038<1179:TSLROA $>2.0 . C O ; 2$.

Johanson, C. M., and Q. Fu, 2009: Hadley cell widening: Model simulations versus observations. J. Climate, 22, 2713-2725, doi:10.1175/2008JCLI2620.1.

Jones, D. A., W. Wang, and R. Fawcett, 2009: High-quality spatial climate data-sets for Australia. Aust. Meteor. Oceanogr. J., 58, 233-248.

Jourdain, N. C., A. Sen Gupta, A. S. Taschetto, C. C. Ummenhofer, A. F. Moise, and K. Ashok, 2013: The Indo-Australian monsoon and its relationship to ENSO and IOD in reanalysis data and the CMIP3/CMIP5 simulations. Climate Dyn., 41, 30733102, doi:10.1007/s00382-013-1676-1.

Kang, S. M., and L. M. Polvani, 2011: The interannual relationship between the latitude of the eddy-driven jet and the edge of the Hadley cell. J. Climate, 24, 563-568, doi:10.1175/2010JCLI4077.1.

Kent, D. M., D. G. C. Kirono, B. Timbal, and F. H. S. Chiew, 2013: Representation of the Australian sub-tropical ridge in the CMIP3 models. Int. J. Climatol., 33, 48-57, doi:10.1002/joc.3406.

Kim, S. T., and J.-Y. Yu, 2012: The two types of ENSO in CMIP5 models. Geophys. Res. Lett., 39, L11704, doi:10.1029/ 2012GL052006.

King, A. D., L. V. Alexander, and M. G. Donat, 2013: Asymmetry in the response of eastern Australia extreme rainfall to lowfrequency Pacific variability. Geophys. Res. Lett., 40, 22712277, doi:10.1002/grl.50427.

Larsen, S. H., and N. Nicholls, 2009: Southern Australian rainfall and the subtropical ridge: Variations, interrelationships, and trends. Geophys. Res. Lett., 36, L08708, doi:10.1029/ 2009GL037786.

Li, G., and S.-P. Xie, 2014: Tropical biases in CMIP5 multimodel ensemble: The Excessive equatorial pacific cold tongue and double ITCZ problems. J. Climate, 27, 1765-1780, doi:10.1175/ JCLI-D-13-00337.1.

Liu, Z., A. Mehran, T. J. Phillips, and A. AghaKouchak, 2014: Seasonal and regional biases in CMIP5 precipitation simulations. Climate Res., 60, 35-50, doi:10.3354/cr01221.

Lucas, C., B. Timbal, and H. Nguyen, 2013: The expanding tropics: A critical assessment of the observational and modeling studies. Wiley Interdiscip. Rev.: Climate Change, 5, 89-112, doi:10.1002/wcc. 251.

Maher, P., and S. C. Sherwood, 2014: Disentangling the multiple sources of large-scale variability in Australian wintertime precipitation. J. Climate, 27, 6377-6392, doi:10.1175/ JCLI-D-13-00659.1.

Meehl, G. A., C. Covey, K. E. Taylor, T. Delworth, R. J. Stouffer, M. Latif, B. McAvaney, and J. F. B. Mitchell, 2007: THE WCRP CMIP3 multimodel dataset: A new era in climate change research. Bull. Amer. Meteor. Soc., 88, 1383-1394, doi:10.1175/ BAMS-88-9-1383.

Meneghini, B., I. Simmonds, and I. N. Smith, 2007: Association between Australian rainfall and the Southern Annular Mode. Int. J. Climatol., 27, 109-121, doi:10.1002/joc.1370.

Meyers, G., P. McIntosh, L. Pigot, and M. Pook, 2007: The years of El Niño, La Niña, and interactions with the tropical Indian Ocean. J. Climate, 20, 2872-2880, doi:10.1175/JCLI4152.1.

Miller, R. L., G. A. Schmidt, and D. T. Shindell, 2006: Forced annular variations in the 20th century Intergovernmental Panel on Climate Change Fourth Assessment Report models. J. Geophys. Res., 111, D18101, doi:10.1029/2005JD006323.

Nguyen, H., C. Lucas, A. Evans, B. Timbal, and L. Hanson, 2015: Expansion of the Southern Hemisphere Hadley cell in response to greenhouse gas forcing. J. Climate, 28, 8067-8077, doi:10.1175/JCLI-D-15-0139.1.

Peirce, C., 1884: The numerical measure of the success of predictions. Science, ns-4, 453-454, doi:10.1126/science.ns-4.93.453-a.

Pook, M. J., and T. Gibson, 1999: Atmospheric blocking and storm tracks during SOP-1 of the FROST Project. Aust. Meteor. Mag., 1, 51-60.

—, J. S. Risbey, P. C. McIntosh, C. C. Ummenhofer, A. G. Marshall, and G. A. Meyers, 2013: The seasonal cycle of blocking and associated physical mechanisms in the Australian region and relationship with rainfall. Mon. Wea. Rev., 141, 4534-4553, doi:10.1175/MWR-D-13-00040.1.

Risbey, J. S., M. J. Pook, P. C. McIntosh, M. C. Wheeler, and H. H. Hendon, 2009: On the remote drivers of rainfall variability in Australia. Mon. Wea. Rev., 137, 3233-3253, doi:10.1175/ 2009MWR2861.1.

, P. C. McIntosh, M. J. Pook, H. A. Rashid, and A. C. Hirst, 2011: Evaluation of rainfall drivers and teleconnections in an ACCESS AMIP run. Aust. Meteor. Oceanogr. J., 61, 91-105.

Saji, N. H., B. N. Goswami, P. N. Vinayachandran, and T. Yamagata, 1999: A dipole mode in the tropical Indian Ocean. Nature, 401 (6751), 360-363.

Scaife, A., T. Woollings, J. Knight, G. Martin, and T. Hinton, 2010: Atmospheric blocking and mean biases in climate models. J. Climate, 23, 6143-6152, doi:10.1175/2010JCLI3728.1.

Seidel, D. J., Q. Fu, W. J. Randel, and T. J. Reichler, 2008: Widening of the tropical belt in a changing climate. Nat. Geosci., $\mathbf{1}$, 21-24, doi:10.1038/ngeo.2007.38.

Sherwood, S. C., 1999: Convective precursors and predictability in the tropical western Pacific. Mon. Wea. Rev., 127, 2977-2991, doi:10.1175/1520-0493(1999)127<2977:CPAPIT>2.0.CO;2.

Taylor, K. E., R. J. Stouffer, and G. A. Meehl, 2012: An overview of CMIP5 and the experiment design. Bull. Amer. Meteor. Soc., 93, 485-498, doi:10.1175/BAMS-D-11-00094.1.

Thompson, D. W. J., and J. M. Wallace, 2000: Annular modes in the extratropical circulation. Part I: Month-to-month variability. J. Climate, 13, 1000-1016, doi:10.1175/1520-0442(2000)013<1000: AMITEC $>2.0 . \mathrm{CO} ; 2$.

Timbal, B., and W. Drosdowsky, 2012: The relationship between the decline of Southeastern Australian rainfall and the strengthening of the subtropical ridge. Int. J. Climatol., 33, 1021-1034, doi:10.1002/ joc.3492.

Trenberth, K. E., 1984: Signal versus noise in the Southern Oscillation. Mon. Wea. Rev., 112, 326-332, doi:10.1175/ 1520-0493(1984)112<0326:SVNITS > 2.0.CO;2.

Ummenhofer, C. C., M. H. England, P. C. McIntosh, G. A. Meyers, M. J. Pook, J. S. Risbey, A. S. Gupta, and A. S. Taschetto, 2009: What causes southeast Australia's worst 
droughts? Geophys. Res. Lett., 36, L04706, doi:10.1029/ 2008GL036801.

Weller, E., and W. Cai, 2013: Realism of the Indian Ocean dipole in CMIP5 models: The implications for climate projections. J. Climate, 26, 6649-6659, doi:10.1175/ JCLI-D-12-00807.1.

Whan, K., B. Timbal, and J. Lindesay, 2014: Linear and nonlinear statistical analysis of the impact of sub-tropical ridge intensity and position on south-east Australian rainfall. Int. J. Climatol., 34, 326-342, doi:10.1002/joc.3689.

Wilks, D. S., 2011: Statistical Methods in the Atmospheric Sciences. 3rd ed. International Geophysics Series, Vol. 100, Academic Press, 704 pp.

Williams, A. A. J., and R. C. Stone, 2009: An assessment of relationships between the Australian subtropical ridge, rainfall variability, and high-latitude circulation patterns. Int. J. Climatol., 29, 691-709, doi:10.1002/ joc. 1732 .

Wright, W., 1994: Seasonal climate summary southern hemisphere (autumn 1993): A second mature ENSO phase. Aust. Meteor. Mag., 43, 205-212.

Zappa, G., L. C. Shaffrey, and K. I. Hodges, 2013: The ability of CMIP5 models to simulate North Atlantic extratropical cyclones. J. Climate, 26, 5379-5396, doi:10.1175/JCLI-D-12-00501.1.

Zhang, X., F. W. Zwiers, G. C. Hegerl, F. H. Lambert, N. P. Gillett, S. Solomon, P. A. Stott, and T. Nozawa, 2007: Detection of human influence on twentieth-century precipitation trends. Nature, 448, 461-465, doi:10.1038/nature06025.

Zheng, F., J. Li, R. T. Clark, and H. C. Nnamchi, 2013: Simulation and projection of the Southern Hemisphere annular mode in CMIP5 models. J. Climate, 26, 9860-9879, doi:10.1175/ JCLI-D-13-00204.1. 